\title{
The role of mesoscopic modelling in understanding the response of dental enamel to mid-infrared radiation
}

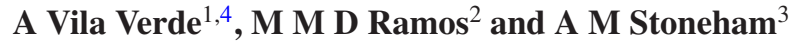 \\ ${ }^{1}$ Department of Chemical Engineering, Fenske Laboratory, The Pennsylvania State University, \\ University Park, PA 16802, USA \\ 2 Department of Physics, University of Minho, 4710-057 Braga, Portugal \\ ${ }^{3}$ London Centre for Nanotechnology and Department of Physics and Astronomy, \\ University College London, Gower Street, London WC1E 6BT, UK \\ E-mail: marta@fisica.uminho.pt
}

Received 20 December 2006, in final form 26 February 2007

Published 25 April 2007

Online at stacks.iop.org/PMB/52/2703

\begin{abstract}
Human dental enamel has a porous mesostructure at the nanometre to micrometre scales that affects its thermal and mechanical properties relevant to laser treatment. We exploit finite-element models to investigate the response of this mesostructured enamel to mid-infrared lasers $\left(\mathrm{CO}_{2}\right.$ at $10.6 \mu \mathrm{m}$ and Er:YAG at $2.94 \mu \mathrm{m})$. Our models might easily be adapted to investigate ablation of other brittle composite materials. The studies clarify the role of pore water in ablation, and lead to an understanding of the different responses of enamel to $\mathrm{CO}_{2}$ and Er:YAG lasers, even though enamel has very similar average properties at the two wavelengths. We are able to suggest effective operating parameters for dental laser ablation, which should aid the introduction of minimally-invasive laser dentistry. In particular, our results indicate that, if pulses of $\approx 10 \mu$ s are used, the $\mathrm{CO}_{2}$ laser can ablate dental enamel without melting, and with minimal damage to the pulp of the tooth. Our results also suggest that pulses with $0.1-1 \mu$ s duration can induce high stress transients which may cause unwanted cracking.
\end{abstract}

\section{Introduction}

The realization that lasers could ablate dental hard tissue with precision has suggested new minimally-invasive methods to treat dental caries. Such methods would conserve healthy dental tissue, and the treated teeth would be stronger and more durable. However, the successful realization of such laser-based methods has proved slower than hoped. Some reasons are economic, like laser cost. But perhaps a more important reason has been the difficulty in choosing the right laser system and optimal operating parameters. The tooth itself

4 Previously at the University of Minho, Portugal. 
complicates that choice because it has a complex microstructure, in which the hard and soft components have different optical absorption and response, so that approaches going beyond simple continuum models are needed for optimization of operating parameters. Further, ablation depends in a highly nonlinear way on parameters such as wavelength, energy flux and pulse duration. Our paper addresses optimization, showing how our mesoscopic modelling methods might identify a suitable laser system and operating conditions to optimally ablate dental enamel.

Laser techniques have three substantial potential advantages over conventional cavity preparation. First, precise and small-scale removal of material is possible. The less tooth tissue removed, the less susceptible the tooth will be to subsequent mechanical damage. It should be possible to produce tunnels of diameter $<0.5 \mathrm{~mm}$ through enamel and the underlying dentine in treating caries starting at occlusal pits and fissures. In such locations, the carious site lies beneath a layer of healthy enamel. Recent work has shown that the bacteria within the dentine may be killed by photochemical means using a photosensitizer activated by light of a specific wavelength introduced through the tunnel access (Williams et al 2004). Secondly, minimal removal makes it easier to avoid reinfection. The small opening-a possible source of the infection-is readily sealed, thus providing mechanical support for the healthy enamel still covering the treated site. In particular, the exposed margin of the access cavity is much smaller than with conventional restorations, thus reducing the risks of marginal leakage and stress failure. This in turn will minimize the potential for bacteria and their by-products to reinfect the tooth. Avoidance of reinfection is extremely important: some $40 \%$ of all caries treatments are for reinfected sites, and each treatment makes tooth failure more probable (NHS Centre for Reviews and Dissemination 1999). A third potential advantage, not discussed here, is the use of computer-controlled ablation with real-time diagnostics of the material removed, which should further enhance conservation of dental material.

Many lasers have been shown to ablate enamel. Lasers in the ultraviolet (UV), visible and infrared (IR) have been used, with pulse durations from femtoseconds to seconds. Analysing the key requirements for a good laser system suggested that the $2.94 \mu \mathrm{m}$ Er:YAG and the $10.6 \mu \mathrm{m} \mathrm{CO}$ lasers could be the most promising candidates for dental treatments. First, for clinical use, the dentists to whom we have spoken seek a relatively economical, easilyoperated laser for which there is an optical fibre delivery system. Femtosecond lasers do not meet these requirements, although they ablate enamel and dentine with precision and cause minimal thermal or mechanical damage (Kruger et al 1999, Rode et al 2002, Serafetinides et al 1996, Neev et al 1996). Secondly, if the laser is to be cost-effective, some dentists would like to use the laser for other standard treatments like soft tissue surgery. Thirdly, there are reports of thermal and mechanical damage and of side effects when using picosecond and nanosecond lasers. Even if such damage is avoidable, it is prudent to start with laser systems that seem to minimize these problems. Picosecond lasers have been tested, but enamel or dentine cracking has been observed (Lizarelli et al 1999, Swift et al 2001, Niemz 1998). Lasers with nanosecond pulses may or may not induce significant thermal or mechanical damage, depending on the wavelength (Patel et al 1994, Lee et al 2000, Papagiakoumou et al 2004, Dela Rosa et al 2004). The most promising laser with nanosecond pulse duration has a wavelength of $193 \mathrm{~nm}$ which causes very little thermal and mechanical damage to teeth because the main mechanism of ablation has a photochemical nature. On the downside, this laser may cause cytotoxic effects, which preclude it from being used in living tissues such as dentine (WilderSmith et al 1997, Ediger et al 1997).

Overall, IR lasers with microsecond pulses, notably the $2.94 \mu \mathrm{m}$ Er:YAG and the $10.6 \mu \mathrm{m}$ $\mathrm{CO}_{2}$ lasers, seem strong candidates, given their ablation performance, ease of operation, potential use in soft tissue procedures and cost. In fact, free-running Er:YAG lasers with 
pulse durations of tens or hundreds of microseconds are already available for dental ablation in the context of conventional dentistry. However, a review of the literature (Vila Verde 2005) shows a need to further optimize the $\mathrm{CO}_{2}$ and Er:YAG laser operating parameters for most effective ablation of enamel and dentine in the context of minimally invasive dentistry. The thermo-mechanical ablation mechanisms induced by these lasers imply that pulse duration and intensity should be carefully regulated so ablation is achieved while carbonization, melting, excessive heating of underlying living tissue or extensive cracking are avoided.

Our paper builds on our previous results and models in investigating the thermomechanical response of healthy enamel to $\mathrm{CO}_{2}$ or Er:YAG laser pulses, with the aim of giving initial guidance as to promising choices of lasers and operating parameters. We concentrate on healthy enamel because a survey of ablation of dental hard tissue indicates that the harder, more brittle, enamel, with its lower ablation rate, poses larger problems than does the porous, less mineralized carious enamel or the softer, less brittle, dentine. The average absorption coefficient in healthy enamel at both $2.94 \mu \mathrm{m}$ and $10.6 \mu \mathrm{m}$ is around $800 \mathrm{~cm}^{-1}$ (Zuerlein et al 1999b, Fried et al 1998b), while reflectivity and scattering are low but similar. (Fried et al 1996, 1997). This might suggest that lasers operating at $2.94 \mu \mathrm{m}$ and at $10.6 \mu \mathrm{m}$ would elicit a similar response in enamel. That is not so. Enamel consists predominantly of water and hydroxyapatite. At $2.94 \mu \mathrm{m}$, hydroxyapatite and water absorb very differently from each other, but at $10.6 \mu \mathrm{m}$ they have similar absorption coefficients. Our initial preliminary studies (Vila Verde et al 2003, 2004, Vila Verde and Ramos 2005b) indicate that these differences have a significant effect on ablation behaviour. The inhomogeneous distribution of hydroxyapatite and water in enamel involves mesostructure at the $\mathrm{nm}$ and $\mu \mathrm{m}$ scales. Any model aiming at explaining the observed differences in the response of enamel to these lasers must include this underlying mesostructure explicitly. Such mesostructure has wide-ranging effects on materials properties (Stoneham and Harding 2003), and its importance in ceramic ablation has been discussed previously (Stoneham et al 1999). Our present analysis explicitly discusses this mesostructure, such as the nanometre-scale pores and a small number of much larger, micrometre-sized regions rich in water and organic material (Batina et al 2004, Ten Cate 1998, Dibdin and Poole 1982). Our models therefore allow us to make predictions as to the laser parameters which are likely to perform best in enamel ablation.

\section{Model description}

\subsection{The physical model}

We shall focus on two models addressing mesostructural issues, namely the small water-pore model and the big water-pore model, each describing one closed pore containing water and surrounded by hydroxyapatite. In both cases, we shall consider a central region in detail, this central region being embedded in a way that recognizes the main mechanical and thermal boundary conditions. With these model systems, we assess the role of pores, and of variations in pore size, on the outcome of ablation by $\mathrm{CO}_{2}$ and Er:YAG lasers. The models capture the main features of enamel mesostructure.

Enamel consists mainly of hydroxyapatite, HA (about $95 \%$ by weight), with small amounts of water $(4 \% \mathrm{w} / \mathrm{w})$ and organic material $(1 \% \mathrm{w} / \mathrm{w})$, mostly located in pores. At the micron scale, enamel is composed of rods with their long-axis roughly perpendicular to the surface of the tooth. The boundaries of each rod (the rod sheath) are known to be richer in water pores. While the pore volume and surface distributions in human dental enamel are not known accurately, evidence suggests that most pores have a characteristic length of order of 10 to $100 \mathrm{~nm}$. A small minority of macropores will be significantly bigger, as mentioned previously 
(Batina et al 2004, Ten Cate 1998), and may be associated with hypoplastic enamel, enamel tufts and spindles. The characteristic mineral concentration and porosity both vary from tooth to tooth, and even according to location in a particular tooth (Wong et al 2004, Kodaka et al 1991). Such variations will affect the outcome of ablation (Apel et al 2002a). The pore connectivity is unknown but, since the pore volume fraction in enamel is small (Dibdin 1993), it seems reasonable to assume that connectivity is low. Consequently, the influence of water pores in the response of healthy enamel to radiation can be evaluated by modelling a single, closed pore as done in this work. Such an approximation might not be valid in the modelling of carious enamel, which has higher porosity and lower mineral content. Our present results relate solely to ablation of healthy enamel. The effect of the laser in the material was reproduced by simply simulating a heat source. This is a good approximation because the laser beam energy can be assumed to convert into thermal energy of the material in a much faster timescale than the laser pulse duration. Thus the dominant parameter governing the response of the tissue to radiation is temperature, and one needs to solve equations that describe the evolution of temperature and related thermal stress in the material. Because the temperature distribution dictates the stress distribution in enamel but, under sub-ablative conditions at least, the stress distribution affects neither the absorption of radiation nor the heat diffusion in the material, the thermal and stress problems can be analysed sequentially. Simultaneously solving the thermal and mechanical stress equations is not necessary.

The small water-pore (SWP) model represents a single nanometre-scale water pore embedded in mineral; it is used to assess the influence of pores at this scale on enamel's response to radiation by $\mathrm{CO}_{2}$ and Er:YAG lasers. By varying only the pore size by a few nanometres, we can establish a relationship between pore size and the maximum temperature and stress reached in the pore for the $\mathrm{CO}_{2}$ and Er:YAG lasers. This model also allows us to see how the laser pulse duration affects intensity of the stress transients experienced in enamel, going beyond our previous analysis of a model of enamel that did not include any details of the microstructure (Vila Verde and Ramos 2006).

The big water-pore (BWP) model includes a micrometer scale pore, thus much bigger than the pore modelled in the SWP model. The BWP model is used to simulate transient heat transfer under Er:YAG and $\mathrm{CO}_{2}$ laser irradiation, and yields the temperature distribution in enamel at length scales of tens of micrometres. It is not necessary to run expensive transient stress simulations with the BWP model to obtain the pressure at the pore. Instead, since the relationship between pore temperature and pressure found from the SWP model is not a function of pore shape or size, we may use the same relationship to infer the magnitude of the pressure at the big water pore.

The pores in these models have a cubic shape for computational convenience. This shape is not realistic for stress calculations for pores of shapes likely to occur in enamel. We avoid the obvious difficulty by working with the pressure in the pores, not the stress in the mineral surrounding them. Whilst the mineral stress distribution around a pore will vary between pores of different shapes, the pressure of the fluid inside the pore is, to first approximation, independent of pore shape and function of the temperature only.

Our models describe sub-ablative conditions only, becoming unphysical when the pore pressure exceeds enamel's ultimate tensile strength of about $70 \mathrm{MPa}$ (Denissen et al 1985), when the pore walls may rupture and thermo-mechanical ablation may start. Strictly, this condition applies to spherical pores only (Majaron et al 1999), but it gives a useful guideline. Thus, for most of the situations we analyse, fracture creating fragments of enamel is not expected, and we can use the ultimate tensile strength as a simple guide to behaviour. In other situations, mesoscopic fracture models will be needed, as discussed by Tsui, Harker and Stoneham in Tsui (2002/2003), but we shall not elaborate on this here. 


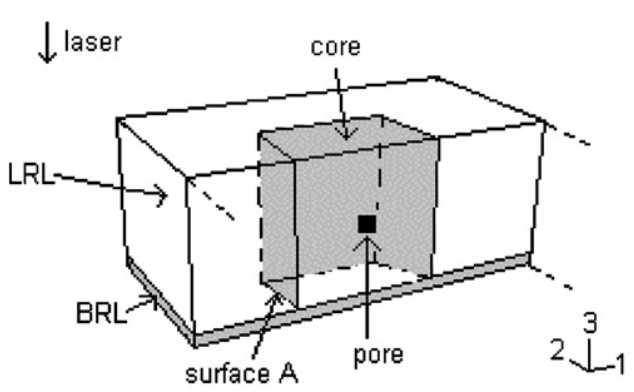

Figure 1. Schematic showing one half of the small water-pore model. Surface A is shown in grey. The core of the model is the entire volume delimited by surface A. The lateral restrain layer (LRL) is the volume delimited by surface A and the outer boundaries of the model. The bottom restrain layer (BRL) comprises the volume also highlighted in grey. A set of labelled Cartesian axes is shown in the image.

\subsection{The small water-pore model}

Our small water-pore model (SWP, figure 1) was developed to investigate the influence of the smaller water pores on the stress and temperature distributions during laser irradiation. In this realization, a single water pore in enamel was represented by a single cubic pore surrounded by HA on all sides. The pore widths all had characteristic dimensions of tens of nanometres.

Conceptually, the model (see figure 1) can be divided into three parts. The core is the region closest to the centre of the model, where the water pore is located. It is bounded by the bottom restrain layer, BRL, and the lateral restrain layer, LRL, which were added so that adequate boundary conditions could be used; their function will be discussed later. The overall model has dimensions $3.1 \times 3.1 \times 1.3 \mu \mathrm{m}^{3}$. This model size allows us to draw a mesh around the pore that is sufficiently fine for accurate calculations, without making these calculations prohibitively long. We have explored the influence of different pore sizes (cubic-pore edge dimensions of $30,70,130$ or $250 \mathrm{~nm}$ ) on the temperature and stress distributions at the end of the laser pulse by performing a series of heat transfer and stress simulations.

\subsection{The big water-pore model}

The big water-pore model was used to assess the response to $10.6 \mu \mathrm{m}$ and $2.94 \mu \mathrm{m}$ radiation of the large water pores in enamel, under a region with very little water. The model comprises several rods, each with the cross-sectional shape given in figure 2(a), oriented relative to the laser as shown in figure 2(b), a geometry that captures the micrometre-scale rod structure of human enamel (Ten Cate 1998). The water-rich rod sheath making the boundary between each rod and its neighbours is not modelled explicitly. Our model explicitly includes a big water pore while all other areas are made of HA. We also include a BRL so as to ensure adequate boundary conditions (see figures 2 and 4). The model dimensions $\left(23 \times 23 \times 35 \mu \mathrm{m}^{3}\right)$ were chosen to provide a cross-sectional area large enough that its size did not significantly influence heat diffusion around the pore. The model length was chosen to be significantly larger than the average absorption depth of radiation in enamel, which is of order $10 \mu \mathrm{m}$ at the selected wavelengths.

Since our SWP model shows that the relationship between pressure and temperature at the water pores is independent of pore size and shape, we have used this same SWP relationship to relate the pore temperature in the BWP model to the pressure in the pore. For this reason, only transient heat transfer simulations were performed with BWP model. 


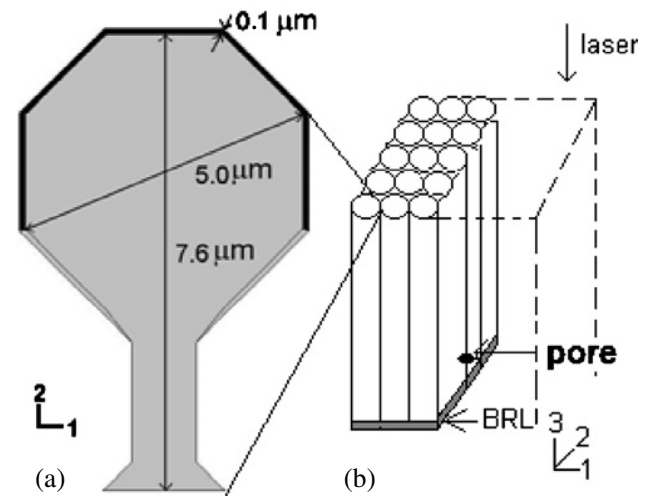

Figure 2. The BWP model. (a) Cross-sectional view of a model for a single enamel rod. The dark area corresponds to the rod sheath and the light area to the actual rod; both parts are composed of hydroxyapatite in our present work. The thinner area is termed the tail or waist while the wider area is commonly described as the head of the rod. (b) Schematic of the big water-pore model, made of several enamel rods like those shown in (a), and showing the location of the bottom restrain layer and of the large pore. A set of labelled Cartesian axes is shown in each image.

\subsection{Implementation of the model}

Most of the details of our implementation have been described in Vila Verde et al (2004), Vila Verde and Ramos (2005a, 2006), Vila Verde (2005), so we concentrate on the key issues only. For convenience, a self-sufficient description of the model and its implementation is also given as supplementary material to this paper. All simulations were performed using the commercial finite-element software Abaqus 6.5-1. We first performed the transient heat transfer simulations with the implicit algorithm available in Abaqus Standard. The initial temperature attributed to all the nodes, which was also the stress-free reference temperature, was $37^{\circ} \mathrm{C}$. Subsequently, the temperature distribution was used as input to the thermal stress analyses, performed with the Explicit algorithm available in Abaqus.

2.4.1. Transient heat transfer simulations. The mineral fraction in the model was given the properties of HA, and the water/organic fraction was given the properties of pure water (see table 1). The temperature dependence of these properties was not included in the models, as our earlier work showed that extreme variations were not expected in the temperature ranges investigated (Vila Verde et al 2004). The energy absorbed per unit volume as a function of depth in each finite element was calculated according to Beer's law (Niemz 1996) accounting for absorption only; scattering and reflectivity of radiation were considered negligible. The absorption coefficient, $\mu$, of hydroxyapatite and water at $\lambda=2.94 \mu \mathrm{m}$ and at $\lambda=10.6 \mu \mathrm{m}$ can be found in table 1. Enamel's reflectance at these wavelengths is less than $13 \%$ (Fried et al 1996, 1997). Scattering is known to be very small at $\lambda=10.6 \mu \mathrm{m}$ (Fried et al 1997). While no experimental information was found for the $2.94 \mu \mathrm{m}$ wavelength, scattering at this wavelength was also taken as zero because enamel's high absorption coefficient, about $800 \mathrm{~cm}^{-1}$ (Zuerlein et al 1999b, Fried et al 1998b), should reduce the effect of scattering on the shape of the enamel volume affected by Er:YAG radiation.

In all the models, the laser spot of radius $0.2 \mathrm{~mm}$ was centred on the pore. At these wavelengths, the optical penetration depth $1 / \mu_{\text {enamel }}$ is about $10 \mu \mathrm{m}$, i.e., the laser intensity falls by a factor $e$ over this distance. The lateral walls of the models were given adiabatic 
Table 1. Material properties used in the simulations. HA: hydroxyapatite; LRL: lateral restrain layer; BRL: bottom restrain layer. A description of how the parameter values used in the LRL and BRL were found is given in Vila Verde et al (2004), Vila Verde and Ramos (2005a, 2006), Vila Verde (2005).

\begin{tabular}{|c|c|c|c|c|c|}
\hline \multirow[b]{2}{*}{ Property } & \multirow[b]{2}{*}{ HA } & \multirow[b]{2}{*}{ Water } & \multicolumn{2}{|c|}{ Model small water-pore } & \multirow{2}{*}{$\begin{array}{l}\text { Model big } \\
\text { water-pore } \\
\text { BRL }\end{array}$} \\
\hline & & & LRL & BRL & \\
\hline & $\begin{array}{l}\text { Zuerlein et al } \\
(1999 b)\end{array}$ & $\begin{array}{l}\text { Zuerlein et al } \\
(1999 b)\end{array}$ & & & \\
\hline \multirow{3}{*}{$\begin{array}{l}\text { Absorption } \\
\text { coefficient }\left(\mathrm{cm}^{-1}\right)\end{array}$} & $\mathrm{CO}_{2}: \quad 825$ & $\mathrm{CO}_{2}: \quad 825$ & $\mathrm{CO}_{2}: \quad 825$ & $\mathrm{CO}_{2}: \quad 825$ & $\mathrm{CO}_{2}: \quad 825$ \\
\hline & $\begin{array}{l}\text { Vila Verde } \text { et al } \\
(2004)\end{array}$ & $\begin{array}{l}\text { Shori et al } \\
(2001)\end{array}$ & Er:YAG: 300 & Er:YAG: 300 & Er:YAG: 300 \\
\hline & Er:YAG: 300 & Er:YAG: 12250 & & & \\
\hline \multirow{3}{*}{$\begin{array}{l}\text { Density at } 37^{\circ} \mathrm{C} \\
\left(\times 10^{3} \mathrm{~kg} \mathrm{~m}^{-3}\right)\end{array}$} & Hughes et al (1989) & Cooper and Le & & Therm. anal.: & 3100 \\
\hline & 3.1 & Fevre (1975) 0.99 & 3.1 & $15.5-46.5$ & \\
\hline & & & & Stress anal: 3.1 & \\
\hline \multirow{2}{*}{$\begin{array}{l}\text { Thermal condct. } \\
\left(\mathrm{J} \mathrm{s} \mathrm{s}^{-1} \mathrm{~m}^{-1}{ }^{\circ} \mathrm{C}^{-1}\right)\end{array}$} & Moroi et al (1993) & Samsonov (1982) & 1.3 & $2.5 \times 10^{-5}$ & $1.3 \times 10^{-4}$ \\
\hline & 1.3 & 0.6 & & & \\
\hline \multirow{3}{*}{$\begin{array}{l}\text { Specific heat } \\
\left(\mathrm{J} \mathrm{kg}^{-1}{ }^{\circ} \mathrm{C}^{-1}\right)\end{array}$} & Moroi et al (1993) & Cooper and Le & 880 & 880 & 880 \\
\hline & 880 & Fevre (1975) & & & \\
\hline & & 4200 & & & \\
\hline \multirow{2}{*}{$\begin{array}{l}\text { Young's modulus } \\
\left(\mathrm{N} \mathrm{m}^{-2}\right)\end{array}$} & Braden (1976) & Not applicable & $1.5 \times 10^{7}$ & $2.89 \times 10^{5}$ & $\mathrm{~N} / \mathrm{A}$ \\
\hline & $1.1 \times 10^{11}$ & & & & \\
\hline Poisson's ratio & $\begin{array}{l}\text { Grenoble et al } \\
\text { (1972) } 0.28\end{array}$ & $\mathrm{~N} / \mathrm{A}$ & 0.28 & 0.28 & $\mathrm{~N} / \mathrm{A}$ \\
\hline \multirow{3}{*}{$\begin{array}{l}\text { Thermal expansion } \\
\text { coefficient }\left({ }^{\circ} \mathrm{C}^{-1}\right)\end{array}$} & Czernuszka (1994) & $\mathrm{N} / \mathrm{A}$ & $\alpha_{\mathrm{xx}}=4 \times 10^{-3}$ & $1.6 \times 10^{-3}$ & $\mathrm{~N} / \mathrm{A}$ \\
\hline & $1.6 \times 10^{-5}$ & & $\alpha_{\mathrm{yy}}=4 \times 10^{-3}$ & & \\
\hline & & & $\alpha_{\mathrm{zz}}=1.6 \times 10^{-5}$ & & \\
\hline
\end{tabular}

boundary conditions because simulations are only performed for tens of microseconds at the most, so lateral heat diffusion is less significant than heat diffusion along the optical axis of the laser beam. The top surfaces of the model do not allow heat exchange with the environment because simple calculations indicate that the energy lost through convection and radiation is less than $1 \%$ of that lost through conduction to the bulk of the tissue.

The role of the bottom restrain layer (BRL) is primarily to replicate heat loss to the bulk of the tissue. To achieve this, the BRL was given a higher density and a lower thermal conductivity $(\kappa)$ than hydroxyapatite. In this way the timescale of heat diffusion to the bulk can be mimicked effectively (Vila Verde and Ramos 2006). We have tested the efficiency of this procedure further by comparing the temperature evolutions as a function of time for models BWP and SWP with results from a model large enough that no BRL was needed for the thermal simulations. The results obtained with the BWP model closely matched those of the larger model. This is not surprising, since the length of the BWP model is comparable with the heat diffusion length for the time intervals analysed. With the SWP model, the temperature still decreases faster than it should, although not as fast as it would if the thermal conductivity of the BRL in the small water-pore model were that of hydroxyapatite. Significantly, the value of the maximum temperature reached compared well with the reference calculation. Overall, the uncertainty is estimated to be in tens of ${ }^{\circ} \mathrm{C}$, so the results are accurate enough to yield useful information. 
2.4.2. Transient stress simulations. The mechanical behaviour of the mineral fraction of dental enamel is reasonably well described by a linear-elastic stress-strain relationship. If mechanical anisotropy can be ignored, the only two properties needed are Young's modulus, $E$, and Poisson's ratio, $v$. Again, the dependence of these properties with temperature was not included. The water/organic content of pores was modelled as a fluid, using an equation of state (EOS) of water, since the water content in enamel is significantly higher that its content in organic material. Other evidence (Giaya and Thompson 2002, Liu et al 2003, Borggreven et al 1980) strongly suggests that the water in HA pores as small as $30 \times 30 \times 30 \mathrm{~nm}^{3}$ behaves like liquid bulk water. We used the EOS for liquid water derived by Lyons (1996) because of its simplicity. Our calculations will show that the water temperature and pressure at the pores are always such that the water never exceeds its boiling point: water vaporization does not occur under the simulated conditions.

As with the thermal simulations, it was necessary to impose adequate boundary conditions for the stress simulations. Simply keeping all external nodes of the models fixed is not a good option, since it does not allow lateral expansion to occur. Periodic boundary conditions are also not adequate for the same reason, since we have no way of allowing changes in the unit cell volume. We have adopted embedding boundary conditions more thoroughly discussed by us elsewhere (Vila Verde and Ramos 2005a, Vila Verde 2005). Briefly, the approach is to give the outer elements of the model (i.e., the LRL and BRL of figure 1) different mechanical properties from the bulk, so that the centre of the model is allowed to expand in a somewhat constrained manner. In effect, the restrain layers (RLs) as a whole impose the boundary conditions to the central part of the models: by adjusting the material properties of the RLs, the centre of the model may effectively reproduce the displacement and stress fields in a micrometre-size piece of enamel which is a part of a tooth. The mechanical properties of the restrain layer must have values such that, for example, nodes in surface A of model SWP (figure 1) experience the same stress and displacement as if they were surrounded by a wider portion of enamel or dentine.

We remark that only the elastic constant $E_{\mathrm{RL}}$ was modified in the transient stress simulations, and that the density of the restrain layers stayed equal to $\rho_{\mathrm{HA}}$. The acoustic impedance of the RLs is thus much smaller than the acoustic impedance of the HA, so sound waves will be reflected at the interfaces between the core of the model and the RLs. Matching the impedance of the core to the impedance of the RLs would simply cause reflections to occur at the outer surfaces of the model instead of at the above-mentioned interfaces, not a marked improvement. If necessary, one could impose a dissipative boundary condition at the RLs while matching their impedance to the impedance of the core of the model; this would minimize reflection, but be expensive computationally. Our chosen boundary conditions should prove adequate to estimate the quasi-static stress at the end of the laser pulse (the stress distribution tens of microseconds after the laser pulse, when the stress transients are no longer important), and this is supported by our results. Our choices of the boundary conditions will introduce uncertainties in stress transients, and we have been cautious in our interpretations of them.

The restrain layer must also account for the thermal expansion of the region it represents and its effect on the central part of the model. The thermal expansion coefficient of the restrain layers, $\alpha_{\mathrm{RL}}$, was thus scaled according to the procedure described in Vila Verde and Ramos (2005a). Only the thermal expansion coefficients along the $x$ and $y$ directions $\left(\alpha_{\mathrm{RL}, x x}\right.$ and $\left.\alpha_{\mathrm{RL}, y y}\right)$ are scaled for the lateral restrain layer, since this layer only deals with the size reduction in these directions. For analogous reasons, only $\alpha_{\mathrm{RL}, z z}$ is scaled for the bottom restrain layer. 

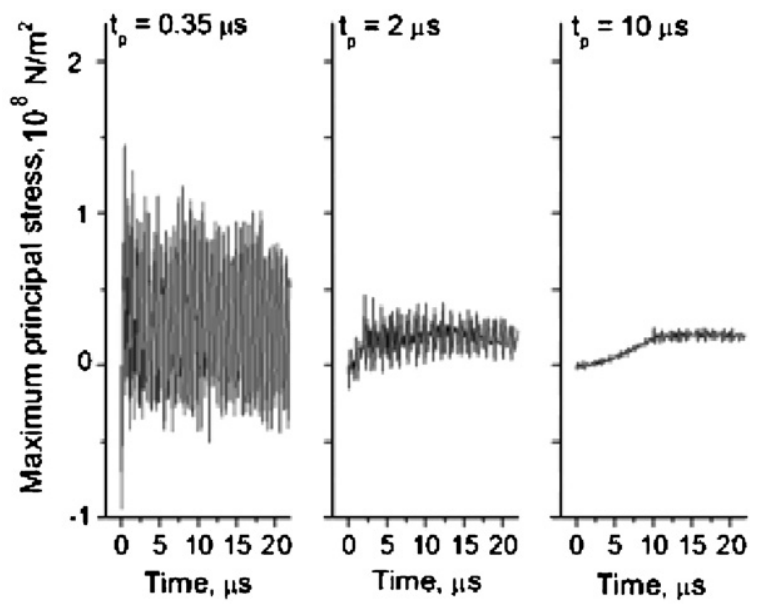

Figure 3. Maximum principal stress around the pore for three $\mathrm{CO}_{2}$ laser pulses of different durations and fluence $0.42 \mathrm{~J} \mathrm{~cm}^{-2}$. The results were obtained using the small water-pore model.

\section{Results and discussion}

\subsection{The effect of different pulse durations}

The influence of the $\mathrm{CO}_{2}$ pulse duration on the stress evolution was investigated using model small water-pore. The results obtained with model SWP for pulse durations $0.35 \mu \mathrm{s}, 2 \mu \mathrm{s}$ and $10 \mu$ s are given in figure 3 . The maximum pulse duration tested was limited to $10 \mu$ s laser pulses, since our previous results show that longer pulse durations would give rise to thermal diffusion outside the irradiated volume and potential damage to the pulp (Vila Verde 2005).

These results suggest that pulse durations close to $0.5 \mu$ s should induce larger stress transients, in excess of enamel's ultimate tensile stress (UTS) of $70 \mathrm{MPa}$ (Denissen et al 1985). Such transients would be sufficient to cause unwanted cracking. Pulses longer than 1-2 $\mu$ s give rise to smaller transient stresses, and are unlikely to cause cracking. The characteristic pulse duration below which one expects to induce high stress transients under laser irradiation is likely to be of the order of the acoustic relaxation time, which is about $2 \mathrm{~ns}$ for enamel under these conditions. That pulse durations of $0.5 \mu$ s may already induce unwanted cracking is a warning against regarding the acoustic relaxation time as anything more than a rough estimate as to pulse durations to avoid high stress transients.

We have assessed the reliability of our results by comparison with our own preliminary theory results and by comparisons with experimental data from other authors. Our preliminary results (Vila Verde and Ramos 2005b) were obtained using an enamel model that did not include any details of enamel's mesostructure and was roughly one order of magnitude larger. Comparison allows us to check the issues of model size and of boundary reflections associated with the lack of dissipative boundary conditions. Our present results give maximum transient stresses about one order of magnitude higher than in the previous work, but the quasi-static stress (i.e., the stress level tens of microseconds after the laser pulse) proves similar in both preliminary and current results. This indicates that the boundary conditions used should indeed be adequate for the study of quasi-static stress. Overall, the comparisons support our conclusion that pulse durations lower than $0.5 \mu$ s should be avoided to minimize high intensity stress transients. Ablation will then take place through the effects of localized quasi-static 
stresses around pores, induced by heating of pore water: cracking will be limited to the irradiated site.

We could not find experimental data for stress transients in enamel for $\mathrm{CO}_{2}$ laser pulses shorter than $1 \mu \mathrm{s}$, so our results cannot be compared directly with experiment. However, experimental observations made using a Q-switched (pulse duration $=150 \mathrm{~ns}$ ) Er:YAG laser on enamel do indicate large transient stresses (Fried et al 1998a). We note that useful comparisons could be made collating the acoustic transients and the ablation threshold of the Er:YAG and $\mathrm{CO}_{2}$ lasers using pulses shorter than $0.5 \mu$ s with those for longer-pulse lasers $(10 \mu \mathrm{s})$. This way one could assess whether the damage and ablation thresholds vary significantly in that pulse duration range. If the stress transients play a significant role in ablation with the shorter pulses, then significant differences in the ablation threshold must be observed between the long and short laser pulses.

The qualitative consistency between previous and current results, and between our results and experiment, suggests that the models, simplistic as they are, do give a reasonable picture of the transient response of enamel to laser irradiation that indicates guidelines as to the optimal pulse duration for ablation of enamel. We suggest that a pulse duration of $10 \mu$ s should be close to optimal for the ablation of enamel using $\mathrm{CO}_{2}$ lasers. First, such pulses do not induce high stress transients. Secondly, such pulses ensure minimal heat diffusion outside the irradiated volume (Vila Verde and Ramos 2006), which should both reduce melting and/or cracking at the boundaries of the ablated site as well as reduce pulp heating. Although dental pulp is far from enamel, excessive pulp heating is known to occur when the tooth is irradiated with mid-infrared lasers with pulse durations of order $100 \mu \mathrm{s}$, and water cooling is normally used to minimize it (Attrill et al 1996, Zach and Cohen 1965). Within our present model, we cannot definitively exclude the need for water cooling when $10 \mu$ s pulses are used. Nevertheless, our results suggest strongly that pulp heating will be much less significant for $10 \mu$ s pulses than when $100 \mu$ s pulses are used. Thirdly, such pulses should maximize the amount of material ablated per pulse. The amount of material ablated per pulse is proportional to the total energy deposited per pulse (Majaron et al 1998), which depends on pulse duration and laser intensity. Therefore, both the pulse duration and the laser intensity should be as high as possible. The maximum intensity of the laser is limited by the onset of plasma in the plume that shields the tissue from incoming radiation (Fried et al 2001).

\subsection{The effect of different water-pore sizes}

We now use the SWP model to establish relationships between the pore temperature and pressure as a function of pore size both for $\mathrm{CO}_{2}$ and for Er:YAG lasers. Our results, given in table 2 for $0.35 \mu$ s pulses, indicate that the temperature and pressure at the pore vary significantly with pore size for the Er:YAG laser, but not for the $\mathrm{CO}_{2}$ laser. The relationship between temperature and pore pressure visible in table 2 agrees very well with that derived from analytical calculations (Vila Verde and Ramos 2005c).

A first conclusion is that the temperature-pressure relationship confirms that pore water has a role in dental enamel ablation by Er:YAG and $\mathrm{CO}_{2}$ lasers. This relationship could not have been inferred from continuum scale models and would have been impossible to calculate with atomistic models. These differences in response of enamel to $\mathrm{CO}_{2}$ and Er:YAG radiation arise from the differences between water and hydroxyapatite absorption coefficients, even though enamel as a whole (of which they are the main constituents) has the same absorption coefficient at the $\mathrm{CO}_{2}$ and Er:YAG wavelengths. Several reasons underlie the variation in temperature with pore size for the Er:YAG laser: there is a larger absorption coefficient of water at this wavelength; the larger pores absorb more energy than smaller ones, and also the larger pores 
Table 2. Maximum temperature and pressure reached at cubic water pores as a function of poresize, following a single $0.35 \mu$ s laser pulse of intensity $I_{0}, 1.2 \times 10^{10} \mathrm{~J} \mathrm{~m}^{-2} \mathrm{~s}^{-1}\left(\mathrm{CO}_{2}\right)$ or $2 \times$ $10^{10} \mathrm{~J} \mathrm{~m}^{-2} \mathrm{~s}^{-1}$ (Er:YAG). For comparison, note that the ultimate tensile strength of enamel is $0.7 \times 10^{8} \mathrm{~N} \mathrm{~m}^{-2}$.

\begin{tabular}{|c|c|c|c|c|}
\hline \multirow[b]{2}{*}{ Pore dimensions $\left(\mathrm{nm}^{3}\right)$} & \multicolumn{2}{|c|}{ Er:YAG } & \multicolumn{2}{|c|}{$\mathrm{CO}_{2}$} \\
\hline & $\begin{array}{l}\text { Maximum } \\
\text { temperature } \\
\left({ }^{\circ} \mathrm{C}\right)\end{array}$ & $\begin{array}{l}\text { Maximum } \\
\text { pressure } \\
\left(\times 10^{8} \mathrm{~N} \mathrm{~m}^{-2}\right)\end{array}$ & $\begin{array}{l}\text { Maximum } \\
\text { temperature } \\
\left({ }^{\circ} \mathrm{C}\right)\end{array}$ & $\begin{array}{l}\text { Maximum } \\
\text { pressure } \\
\left(\times 10^{8} \mathrm{~N} \mathrm{~m}^{-2}\right)\end{array}$ \\
\hline $30 \times 30 \times 30$ & 110 & 0.9 & 150 & 1.6 \\
\hline $70 \times 70 \times 70$ & 120 & 1.0 & 150 & 1.6 \\
\hline $130 \times 130 \times 130$ & 140 & 1.4 & 150 & 1.6 \\
\hline $250 \times 250 \times 250$ & 220 & $-{ }^{\mathrm{a}}$ & 150 & 1.6 \\
\hline
\end{tabular}

${ }^{a}$ Not obtained because the equation of state used is not valid at this temperature.

have smaller area-to-volume ratios and so lose heat less rapidly to their surroundings than smaller pores. Small and large pores experience the same temperature and pressure with the $\mathrm{CO}_{2}$ laser since, at this wavelength, water and mineral have similar absorption coefficients.

A second conclusion suggested by the temperature-pressure relationship is that the $10.6 \mu \mathrm{m} \mathrm{CO}$ laser should be perfectly capable of ablating enamel at temperatures lower than the $800-1200{ }^{\circ} \mathrm{C}$ that cause melting (Zuerlein et al 1999b ). The underlying reason is the very high pressure created in the enamel water pores by the thermal expansion of liquid water at temperatures below water's boiling point (at that pressure). Since the $\mathrm{CO}_{2}$ laser can also be used for soft tissue ablation and cauterization, it is potentially a much more cost-effective option for laser dentistry than the more popular Er:YAG.

Thirdly, our results suggest that the $\mathrm{CO}_{2}$ laser should provide more reproducible results than the Er:YAG laser. We anticipate $\mathrm{CO}_{2}$ lasers should give a smaller sample-to-sample variation than Er:YAG lasers in the ablation threshold of enamel and in the size of the plume particulates. This is because the $\mathrm{CO}_{2}$ laser causes all water pores at a given distance from the surface of the tooth to reach the temperature necessary to induce ablation simultaneously, irrespective of their size, whereas this is not so for the Er:YAG laser. The ablation threshold of enamel by free-running Er:YAG laser (with its characteristic macropulse composed of short micropulses of duration $0.5-5 \mu \mathrm{s}$ ) has indeed been shown to vary greatly between 2.5 and $20 \mathrm{~J} \mathrm{~cm}^{-2}$ (Apel et al 2002a). Unfortunately, equivalent experiments for the $\mathrm{CO}_{2}$ laser have not been reported.

Lastly, these results indicate that both $\mathrm{CO}_{2}$ and Er:YAG lasers may cause unwanted cracking when used to treat the surface of enamel so that it becomes resistant to acid attacks by cariogenic bacteria, a line of treatment currently being investigated by several groups (Apel et al 2005, Tepper et al 2004). The temperatures $\left(400-1000{ }^{\circ} \mathrm{C}\right)$ needed to achieve the intended carbonate loss (Zuerlein et al 1999a) will be more than sufficient to induce cracking through thermal expansion of pore water. Unwanted cracking has indeed been reported for enamel surface modification using the Er:YAG laser, but not for the $\mathrm{CO}_{2}$ laser (Apel et al 2005, 2002b). In using $\mathrm{CO}_{2}$ lasers to create acid resistant surfaces, researchers often use fluences high enough to induce melting in a thin surface layer, when no cracks would be detected. Our results suggest that cracks may indeed form underneath the melted layer, and steps should be taken to check whether such cracks in fact occur.

We have used the big water-pore model to assess the differences in the response of enamel to $\mathrm{CO}_{2}$ and Er:YAG radiation when micrometre-size pores exist. The results obtained with model big water-pore (figure 4) suggest that, if used over enamel regions containing very large pores, the Er:YAG laser may induce more severe deep cracking and with much greater 


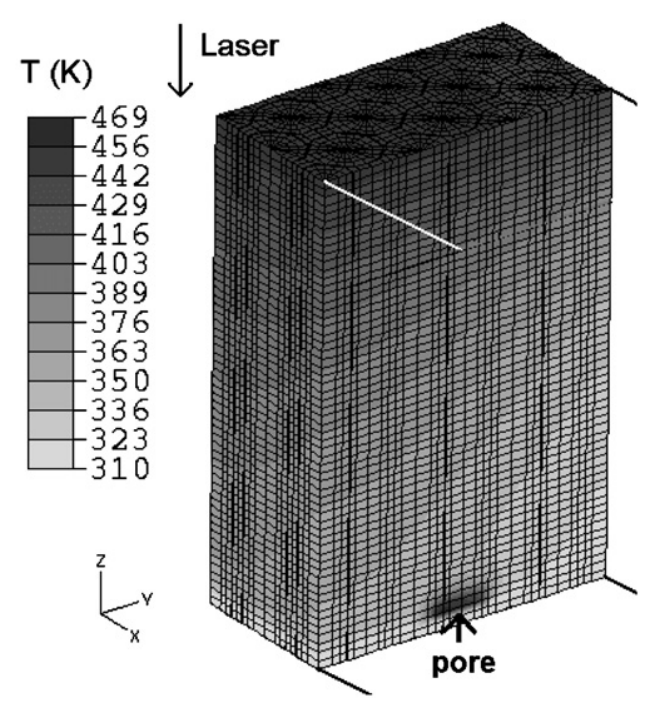

Figure 4. Temperature (in ${ }^{\circ} \mathrm{K}$ ) distribution in the BWP model, illustrating how the Er:YAG laser may cause very high temperatures (higher than at the surface) in water-rich regions $35 \mu \mathrm{m}$ deep inside the model, something not observed for the $\mathrm{CO}_{2}$ laser and an identical enamel model. Only half of the model is shown so that the pore is visible. Pulse duration $=2 \mu \mathrm{s}, I_{0}=6.3 \times$ $10^{9} \mathrm{~J}\left(\mathrm{~m}^{2} \mathrm{~s}\right)^{-1}$.

probability than the $\mathrm{CO}_{2}$ laser. Figure 4 shows results when there is a big pore located around $35 \mu \mathrm{m}$ below the surface of enamel. This reaches the same high temperature as the very surface of enamel when the Er:YAG laser is used whereas, when the $\mathrm{CO}_{2}$ laser is used (image not shown), the pore stays at the same temperature as its direct surroundings.

This potential effect of the Er:YAG laser is particularly troublesome because it may induce deep cracks in enamel that may go undetected because they are not visible at the surface. Such cracks could both decrease the tooth's mechanical strength and contribute to its reinfection. Experimental studies are needed to see whether such subsurface cracks are representative enough to become a problem in a clinical setting. Suitable experiments might test the relative mechanical robustness of samples irradiated with Er:YAG lasers and those treated with $\mathrm{CO}_{2}$ lasers.

\section{Conclusions}

Our mesoscopic model gives guidelines to optimize the ablation of dental hard tissue. The results suggest that the $\mathrm{CO}_{2}$ laser with $10 \mu$ s pulses may ablate enamel at temperatures far from its melting point. The laser pulse should not be shorter than $1 \mu$ s to avoid high stress transients and associated mechanical damage, like cracking. Nor should the pulses exceed about $10 \mu \mathrm{s}$ to minimize heat diffusion outside the irradiated area (Vila Verde and Ramos 2006). These results are reasonably well defined, and are contrary to commonly held views that using the $\mathrm{CO}_{2}$ laser to ablate enamel will necessarily induce significant thermal damage, like hard tissue melting or excessive pulp heating. Published experiments have shown that $\mathrm{CO}_{2}$ laser with pulse durations close to $10 \mu$ s could indeed ablate enamel (Fried et al 2001). Our present work indicates that $10 \mu$ s pulses are close to optimal, suggesting that Fried and Featherstone's results are not only encouraging, but close to optimal for this wavelength. Given that the $\mathrm{CO}_{2}$ laser can also be used for soft tissue procedures, it would seem a more cost-effective option for 
laser dentistry than the Er:YAG laser, currently commercialized to ablate dental hard tissue. Our results also suggest that both Er:YAG and $\mathrm{CO}_{2}(10.6 \mu \mathrm{m})$ lasers may cause cracking at sub-ablative fluences and relatively low temperatures. Thus it may not be prudent to irradiate enamel with the aim of making it more resistant to acid attacks.

Our results highlight the importance of including critical microstructural features when modelling ablation of composite ceramic materials. Such mesoscopic detail appears to be key to the successful modelling of ablation of materials such as carious enamel and dentine, composite dental fillings from a previous restoration, or bone, especially in the proximity of sensitive tissue. Mesoscopic modelling is also indispensable if we want to optimize ablation procedures of living tissues like bone or enamel for different stages in human development. Thus, laser parameters for ablation of osteoporotic bone or children's enamel are likely to be different from parameters appropriate for those materials in healthy adults. While our particular models include many details specific to enamel, developing equivalent approaches for other mesostuctured materials should be easily accomplished.

\section{Acknowledgments}

This work was supported by the Portuguese Foundation for Science and Technology (FCT) through the European Community Fund FEDER under project no. POCTI/ESP/37944/2001. AVV is also indebted to FCT for financial support under PhD grant no. SFRH/BD/4725/2001 and wishes to thank R K Campen, G Dias, G Pearson and J Carneiro for helpful discussions in the course of this work.

\section{References}

Apel C, Meister J, Gotz H, Duschner H and Gutknecht N 2005 Structural changes in human dental enamel after subablative erbium laser irradiation and its potential use for caries prevention Caries Res. 39 65-70

Apel C, Meister J, Ioana R S, Franzen R, Hering P and Gutknecht N 2002a The ablation threshold of Er:YAG and Er:YSGG laser radiation in dental enamel Lasers Med. Sci. 17 246-52

Apel C, Meister J, Schmitt N, Graber H G and Gutknecht N 2002b Calcium solubility of dental enamel following sub-ablative Er:YAG and Er:YSGG laser irradiation in vitro Lasers Surg. Med. 30 337-41

Attrill D C, Farrar S R, Blinkhorn A S, Davies R M, Dickinson M R and King T A 1996 Proc. SPIE 2922 220-7

Batina N, Renugopatakrishnan V, Lavin P N C, Guerrero J C H, Morales M, Garduno-Juarez R and Lakka S L 2004 Ultrastructure of dental enamel afflicted with hypoplasia: An atomic force microscopic study Calcif. Tissue Int. 74 294-301

Borggreven J M P M, Driessens F C M and Vandijk J W E 1980 Diffusion through bovine tooth enamel as related to the water-structure in its pores Arch. Oral Biol. 25 345-8

Braden M 1976 Biophysics of the tooth Physiology of Oral Tissues ed Y Kawamura (New York: S Karger AG, Basel)

Cooper J R and Le Fevre E J 1975 Thermophysical Properties of Water Substance-Student's Tables in SI Units (London: Edward Arnold)

Czernuszka J 1994 Hydroxyapatite The Encyclopedia of Advanced Materials 1st edn ed D Bloor, M C Flemings, R Brook, S Mahajan and R Cahn (Cambridge: Elsevier Science)

Dela Rosa A, Sarma A V, Le C Q, Jones R S and Fried D 2004 Peripheral thermal and mechanical damage to dentin with microsecond and sub-microsecond $9.6 \mathrm{~mm}, 2.79 \mathrm{~mm}$, and $0.355 \mathrm{~mm}$ laser pulses Lasers Surg. Med. 35 214-28

Denissen H, Mangano C and Venini G 1985 Hydroxyapatite Implants (Padua: Piccin Nuova Libraria, SPA)

Dibdin G H 1993 The water in human dental enamel and its diffusional exchange measured by clearance of tritiatedwater from enamel slabs of varying thickness Caries Res. 27 81-6

Dibdin G H and Poole D F G 1982 Surface-area and pore-size analysis for human-enamel and dentine by water-vapor sorption Arch. Oral Biol. 27 235-41

Ediger M N, Pettit G H and Matchette L S 1997 In vitro measurements of cytotoxic effects of $193 \mathrm{~nm}$ and $213 \mathrm{~nm}$ laser pulses at subablative fluences Lasers Surg. Med. 21 88-93 
Fried D, Glena R E, Featherstone J D B and Seka W 1997 Permanent and transient changes in the reflectance of CO 2 laser-irradiated dental hard tissues at $\lambda=9.3,9.6,10.3$, and $10.6 \mathrm{~mm}$ and at fluences of $1-20 \mathrm{~J} / \mathrm{cm}^{2}$ Lasers Surg. Med. 20 22-31

Fried D, Ragadio J, Akrivou M, Featherstone J, Murray M W and Dickenson K M 2001 Dental hard tissue modification and removal using sealed transverse excited atmospheric-pressure lasers operating at 9.6 and 10.6 micrometers J. Biomed. Opt. 6 231-8

Fried D, Shori R and Duhn C 1998a Proc. SPIE 3248 78-85

Fried D, Visuri S R, Featherstone J D B, Walsh J, Seka W, E G R, McCormack S M and Wigdor H A 1996 Infrared Radiometry of Dental Enamel During Er:YAG and Er:YSGG Laser Irradiation J. Biomed. Opt. $1455-65$

Fried D, Zuerlein M J, Featherstone J, Seka W, Duhn C and McCormack S M 1998b IR laser ablation of dental enamel: mechanistic dependance on the primary absorber Appl. Surf. Sci. 127-129 852-6

Giaya A and Thompson R W 2002 Water confined in cylindrical micropores J. Chem. Phys. 117 3464-75

Grenoble D E, Katz J L, Dunn K L, Gilmore R S and Murty K L 1972 The elastic properties of hard tissues and apatites J. Biomed. Mater. Res. 6 221-3

Hughes J M, Cameron M and Crowley K D 1989 Structural variations in natural F, OH, and Cl apatites Am. Mineral. $74870-6$

Kodaka T, Debari K and Kuroiwa M 1991 Mineral-content of the innermost enamel in erupted human teeth J. Electron Microsc. 40 19-23

Kruger J, Kautek W and Newesely H 1999 Femtosecond-pulse laser ablation of dental hydroxyapatite and singlecrystalline fluoroapatite Appl. Phys. A 69 S403-S407

Lee C, Ragadio J and Fried D 2000 Proc. SPIE 3910 193-203

Liu Y-C, Wang Q and Lu L-H 2003 Water confined in nanopores: its molecular distribution and diffusion at lower density Chem. Phys. Lett. $381210-5$

Lizarelli R F Z, Kurachi C, Misoguti L, Bagnato V S and Akrivou M 1999 Characterization of enamel and dentin response to Nd:YAG picosecond laser ablation J. Clin. Laser Med. Surg. 17 127-31

Lyons C G 1996 Simple equation of state for dense fluids J. Mol. Liq. 69 269-81

Majaron B, Plestenjak P and Lukac M 1999 Thermo-mechanical laser ablation of soft biological tissue: modeling the micro-explosions Appl. Phys. B $6971-80$

Majaron B, Sustercic D, Lukac M, Skaleric U and Funduk N 1998 Heat diffusion and debris screening in Er : YAG laser ablation of hard biological tissues Appl. Phys. B 66 479-87

Moroi H H, Okimoto K, Moroi R and Terada Y 1993 Numeric approach to the biomechanical analysis of thermal effects in coated implants Int. J. Prosthodont. 6 564-72

Neev J, DaSilva L B, Feit M D, Perry M D, Rubenchik A M and Stuart B C 1996 Ultrashort pulse lasers for hard tissue ablation IEEE J. Sel. Top. Quantum Electron. 2 790-800

NHS Centre for Reviews and Dissemination 1999 Effective Health Care: Dental Restoration: What Type of Filling? (York: NHS Centre for Reviews and Dissemination, University of York)

Niemz H M 1996 Laser-Tissue Interactions_Fundamentals and Applications (Berlin: Springer)

Niemz M H 1998 Proc. SPIE 3255 84-91

Papagiakoumou E, Papadopoulos D N, Khabbaz M G, Makropoulou M I and Serafetinides A 2004 The influence of the Q-switched and free-running Er:YAG laser beam characteristics on the ablation of root canal dentine Appl. Surf. Sci. $233234-43$

Patel B C M, Moss J and Pearson G J 1994 Excimer-laser (248 nm) drilling of tooth tissue-preliminary investigation Lasers Lasers Med. Sci. $9243-8$

Rode A V, Gamaly E G, Luther-Davies B, Taylor B T, Dawes J, Chan A, Lowe R M and Hannaford P 2002 Subpicosecond laser ablation of dental enamel J. Appl. Phys. 92 2153-8

Samsonov G V (ed) 1982 The Oxide Handbook (New York: IFI /Plenum)

Serafetinides A, Makropoulou M I, Kar A K and Khabbaz M 1996 Proc. SPIE 2922 200-8

Shori R K, Walston A A, Stafsudd O M, Fried D and Walsh J T 2001 Quantification and modeling of the dynamic changes in the absorption coefficient of water at $\lambda=2.94 \mathrm{~mm}$ IEEE J. Sel. Top. Quantum Electron. 7 959-70

Stoneham A M and Harding J H 2003 Not too big, not too small: The appropriate scale Nature Mater. 2 77-83

Stoneham M, Ramos M M D and Ribeiro R M 1999 The mesoscopic modelling of laser ablation Appl. Phys. A 69 S81-6

Swift E J, Edwards G S, Perdigao J, Thompson J Y, Nunes M F, Ruddell D E and Negishi A 2001 Free-electron laser etching of dental enamel J. Dent. $29347-53$

Ten Cate R (ed) 1998 Oral Histology-Development, Structure and Function (London: Mosby)

Tepper S A, Zehnder M, Pajarola G F and Schmidlin P R 2004 Increased fluoride uptake and acid resistance by $\mathrm{CO}_{2}$ laser-irradiation through topically applied fluoride on human enamel in vitro J. Dent. 32 635-41

Tsui M 2002/2003 Laser ablation: fracture model M. Sci. Project Report University College London, UK 
Vila Verde A 2005 Modelling of dental laser ablation PhD Thesis University of Minho Braga, Portugal

Vila Verde A and Ramos M M D 2005a Boundary conditions for 3-D dynamic models of ablation of ceramics by pulsed mid-infrared lasers Appl. Surf. Sci. 247 354-61

Vila Verde A and Ramos M M D 2005b Proc. SPIE 5687 69-79

Vila Verde A and Ramos M M D 2005c Modelling the influence of pore size on the response of materials to infrared lasers - An application to human enamel Appl. Surf. Sci 248 446-9

Vila Verde A and Ramos M M D 2006 The influence of pulse duration on the stress levels in ablation of ceramics: a finite element study Appl. Surf. Sci. 252 4511-5

Vila Verde A, Ramos M M D, Ribeiro R M and Stoneham M 2003 Proc. SPIE 4950 72-82

Vila Verde A, Ramos M M D, Stoneham M and Ribeiro R M 2004 Mesoscopic modelling of the interaction of infrared lasers with composite materials: an application to human dental enamel Appl. Surf. Sci. 238 410-4

WilderSmith P, Lin S, Nguyen A, Liaw L H, Arrastia A M A, Lee J P and Berns M W 1997 Morphological effects of ArF excimer laser irradiation on enamel and dentin Lasers Surg. Med. 20 142-8

Williams J A, Pearson G J, Colles M J and Wilson M 2004 The photo-activated antibacterial action of toluidine blue $\mathrm{O}$ in a collagen matrix and in carious dentine Caries Res. 38 530-6

Wong F S L, Anderson P, Fan H and Davis G R 2004 X-ray microtomographic study of mineral concentration distribution in deciduous enamel Arch. Oral Biol. 49 937-44

Zach L and Cohen G 1965 Pulp response to externally applied heat Oral Surg. Oral Med. Oral Pathol. Oral Radiol. Endod. 19 515-30

Zuerlein M J, Fried D and Featherstone J D B 1999a Modeling the modification depth of carbon dioxide laser treated-dental enamel Lasers Surg. Med. 25 335-47

Zuerlein M J, Fried D, Featherstone J D B and Seka W 1999b Optical properties of dental enamel in the mid-IR determined by pulsed photothermal radiometry IEEE J. Sel. Top. Quantum Electron. 5 1083-9 